\title{
Effect of ion exchange substrate on grass root development and cohesion of sandy soil
}

\author{
Mariola Chomczyńska ${ }^{*}$, Vladimir Soldatov ${ }^{2}$, Henryk Wasag $^{1}$, and Marcin Turski ${ }^{3}$ \\ ${ }^{1}$ Faculty of Environmental Engineering, Lublin University of Technology, Nadbystrzycka 40B, Lublin 20-618, Poland \\ ${ }^{2}$ Institute of Physical Organic Chemistry, Belarus National Academy of Science, Surganov 13, Minsk 220072, Belarus \\ ${ }^{3}$ Institute of Agrophysics, Polish Academy of Sciences, Doświadczalna 4, 20-290 Lublin, Poland
}

Received April 30, 2016; accepted June 8, 2016

\begin{abstract}
A b s t r a c t. The effect of small additions of ion exchange substrate (nutrient carrier) on root development and accompanying ground cohesion (characterized by its penetration resistance) was studied. During two pot experiments Dactylis glomerata L. was grown on sand and its mixture with 1 and $2 \%(\mathrm{v} / \mathrm{v})$ of ion exchange substrate, respectively. The number and total length of roots were measured during the first test. Penetration resistance was measured with a pentrologger, following the second experiment. After six weeks of growth, number and length of roots in sand mixture with 1 and $2 \%$ substrate was greater than in sandonly medium by $211-287$ and $273-323 \%$, respectively. At the same time, penetration resistance in series with substrate additions was significantly higher than in control medium at depth of $2.5-7(8) \mathrm{cm}$, whereas after 12 week of growth, penetration resistance in series with 1 and $2 \%$ substrate additions was significantly greater than in control sand at the whole analyzed depth. The highest resistance values in media with substrate additions 2-2.5 times greater than those in sand alone - were observed at depth of 3.5-4.0 cm. Higher resistance of sand-substrate mixtures results from more intensive development of root systems, forming a mesh which binds sand particles. Such media would be less susceptible to erosion.

$\mathrm{K}$ e y w o r d s: ion exchange substrate, soil cohesion, soil erosion, Dactylis glomerata L., treatments
\end{abstract}

\section{INTRODUCTION}

The use of synthetic ion exchange resins in soil and environment studies has attracted much attention and many journal articles have been published on this matter. The rich overview of historic and current developments in the use of ion exchange techniques in soil research was presented by

*Corresponding author e-mail: m.chomczynska@wis.pol.lublin.pl
Qian and Schoenau (2002). It is commonly known that the plant growth on sandy soils can be supported by intensive fertilization. Ion exchange substrates can be used for this purpose as an addition or alternative to organic or mineral fertilizers because they contain the full set of nutrient elements in chemically bound form and high concentrations. What is more, they do not cause salinization of the irrigation water, do not undergo wind and water erosion and they are sterile and easily sterilisable.

The ion exchange substrates are mixtures of cation and anion exchangers loaded with macro- and micronutrient ions in appropriate ratios. The preparation of ion exchange substrates is based on providing the mixtures of cation and anion exchangers with the ionic composition that assures the availability of biogenic elements for plants to the same degree as in nutrient solutions. The ion exchange substrates differ from conventional fertilizers in several respects. The ions of nutrients are bound to the polymer matrices of the cation or anion exchanger and are not washed out by rainfalls. A high concentration of the nutrient ions in the ion exchange substrates ( $\sim 8 \%$ of mass) does not cause osmotic shock of the root tissues and many biological experiments have shown that plants grow successfully in the pure ion exchange substrate with high yield (70-80 g of dry biomass per $1 \mathrm{~kg}$ of dry substrate). The ion exchangers present in the substrates retain only ions of nutrient elements and deliver them to the rhizosphere in exchange to the root ionic metabolites (mainly $\mathrm{H}^{+}, \mathrm{HCO}_{3}^{-}$) (Soldatov, 1988). The ion exchange substrates are produced in limited amounts in

(C) 2016 Institute of Agrophysics, Polish Academy of Sciences 
the Institute of Physical Organic Chemistry of the Belarus National Academy of Sciences (under trade name Biona). They differ from each other in the type of the ion exchangers used as their constituents, nutrients concentrations and their proportions. These factors can be used to control $\mathrm{pH}$ of soil solution contacting plant roots after introducing ion exchange substrate into the ground (Soldatov, 1998; Soldatov and Peryskina, 1985).

The advantages of ion exchange substrates (richness in nutrients, activity as natural soil exchange complex, stability to decomposition and erosion) led to the idea of using them for biological soil restoration and improvement of fertility and mechanical characteristics of sandy soils. The Lublin University of Technology, Poland, has commenced modeling studies with different kinds of ion exchange substrates as fertilizer additions to sand (Soldatov et al., 1997; Wasag et al., 2000). In these tests the main objective was to maximize the plant biomass. It has been shown that addition of one volume percent of the substrate is sufficient for the fertilization of barren grounds. The influence of substrate addition on the development of plant root systems, which is important for the improvement of stabilization and anti-erosive function of plants, has not been studied so far. Therefore, the aim of present studies was to determine the effect of small additions of ion exchange substrate on

T a b l e 1. Contents of available macronutrients in sand (mg per $100 \mathrm{~g})$

\begin{tabular}{cccccc}
\hline $\mathrm{N}^{*}$ & $\mathrm{P}$ & $\mathrm{K}$ & $\mathrm{Mg}$ & $\mathrm{Ca}$ & $\mathrm{S}$ \\
\hline $\begin{array}{l}0.20\left(\mathrm{~N}-\mathrm{NH}_{4}\right) \\
<0.13\left(\mathrm{~N}_{4} \mathrm{NO}_{3}\right)\end{array}$ & 0.48 & $<1.99$ & 1.00 & 4.41 & $0.53\left({\left.\mathrm{~S}-\mathrm{SO}_{4}\right)}\right.$ \\
\hline
\end{tabular}

*Determined in extract: $\mathrm{N}-1 \% \mathrm{~K}_{2} \mathrm{SO}_{4}, \mathrm{P}-0.04 \mathrm{M}$ $\left(\mathrm{CH}_{3} \mathrm{CHOHCOO}\right)_{2} \mathrm{Ca}, \mathrm{K}-0.04 \mathrm{M}\left(\mathrm{CH}_{3} \mathrm{CHOHCOO}\right)_{2} \mathrm{Ca}$, $\mathrm{Mg}-0.0125 \mathrm{M} \mathrm{CaCl}_{2}, \mathrm{Ca}-0.03 \mathrm{M} \mathrm{CH} \mathrm{CHOH}_{3} \mathrm{~S}-0.5 \mathrm{M}$ $\mathrm{CH}_{3} \mathrm{COOH}+0.25 \mathrm{M} \mathrm{CH}_{3} \mathrm{COONH}_{4}$.

T a b l e 2. The mass percent of monoionic forms in $100 \mathrm{~g}$ of the ion exchange substrate

\begin{tabular}{cccccc}
\hline \multicolumn{5}{c}{ Form } \\
\hline $\mathrm{NO}_{3}^{-}$ & $\mathrm{H}_{2} \mathrm{PO}_{4}^{-}$ & $\mathrm{SO}_{4}^{2-}$ & $\mathrm{Ca}^{2+}$ & $\mathrm{Mg}^{2+}$ & $\mathrm{K}^{+}$ \\
\hline 15.5 & 7.6 & 24.7 & 40.5 & 6.9 & 4.8 \\
\hline
\end{tabular}

the development of plant root systems and accompanying variations of cohesion characteristics of the ground characterized by its penetration resistance.

\section{MATERIAL AND METHODS}

The studies were performed with Dactylis glomerata L. (var. Amba) (orchard grass) used as the test species recommended for plant restoration mixtures (Maciak, 1999). D. glomerata is one of the most common grass species in Poland. It grows on moderately wet and dry mineral soils and on fertile peat soils.

The sand from sand mine in Gołab near Puławy (Eastern Poland) was used in the research. Its granulometric composition (determined by laser diffraction method (Sochan et al., 2012)) was the following:

$-2-1 \mathrm{~mm}-0 \%$;

$-1-0.5 \mathrm{~mm}-17.7 \%$

$-0.5-0.25 \mathrm{~mm}-54.3 \%$;

$-0.25-0.1 \mathrm{~mm}-27.7 \%$

$-0.1-0.05 \mathrm{~mm}-0.06 \%$

$-<0.05 \mathrm{~mm}-0.3 \%$.

The $\mathrm{pH}$ value of sand-water extract was 6.01. The contents of macronutrients available for plants in the sand were determined according to Polish standards (Lityński and Jurkowska, 1982; Ostrowska et al., 1991). Chemical analysis indicated that sand was deficient in available macronutrients (Table 1).

The ion exchange substrate was prepared by mixing monoionic $\mathrm{K}^{+}, \mathrm{Mg}^{2+}, \mathrm{Ca}^{2+}$ forms of the cation exchanger (KU-2) and $\mathrm{NO}_{3}^{-}, \mathrm{H}_{2} \mathrm{PO}_{4}^{-}$and $\mathrm{SO}_{4}^{2-}$ forms of the anion exchanger (EDE-10P). The cation contents in the monoionic form samples were determined by means of ICP spectrometer (Jobin Yvon 238 Ultrace) in the extracts obtained by substituting the target ions with $\mathrm{H}^{+}$ions. The contents of all anions in the monoionic form samples were determined using ion chromatography (DIONEX ICS-3000) in the extracts obtained by the complete substitution of the target ions with $\mathrm{OH}^{-}$. The percentage of different ionic forms of ion exchangers and the contents of nutrient ions in the substrate are given in Tables 2 and 3 , respectively.

The effect of the ion exchange substrate addition on the development of plant root system was studied in the first experiment. Three series of media were prepared for the pot tests: the control series with sand and two test series with homogenous mixture of the sand with 1 and $2 \%(\mathrm{v} / \mathrm{v})$ of the substrate $(\mathrm{S}+1 \%$ and $\mathrm{S}+2 \%)$, respectively. Eight pots filled with $4.14 \mathrm{dm}^{3}$ of the medium were used in each series. Individual pots (length $-24 \mathrm{~cm}$, width $-11.5 \mathrm{~cm}$, depth $-21 \mathrm{~cm}$ ) were equipped with

T a b l e 3. Contents of macronutrient ions in the ion exchange substrate (mmol per $100 \mathrm{~g}$ )

\begin{tabular}{cccccccc}
\hline Ion & $\mathrm{NO}_{3}^{-}$ & $\mathrm{H}_{2} \mathrm{PO}_{4}^{-}$ & $\mathrm{SO}_{4}{ }^{-2}$ & $\mathrm{Ca}^{2+}$ & $\mathrm{Mg}^{2+}$ & $\mathrm{K}^{+}$ & $\mathrm{pH}$ \\
\hline Content & 65.0 & 23.6 & 216.6 & 367.7 & 66.0 & 18.8 & $4.45^{*}$ \\
\hline
\end{tabular}

${ }^{*} \mathrm{pH}$ value of the resultant solution after mixing ion exchange substrate with the reference nutrient solution $\left(\mathrm{Ca}\left(\mathrm{NO}_{3}\right)_{2} \cdot 4 \mathrm{H}_{2} \mathrm{O}-0.710 \mathrm{~g}{ }^{-1}\right.$, $\left.\mathrm{MgSO}_{4} \cdot 7 \mathrm{H}_{2} \mathrm{O}-0.240 \mathrm{~g} \mathrm{l}^{-1}, \mathrm{KNO}_{3}-0.708 \mathrm{~g} \mathrm{l}^{-1}, \mathrm{KH}_{2} \mathrm{PO}_{4}-0.272 \mathrm{~g} \mathrm{l}^{-1}\right)$. 
a single transparent wall that enabled root development to be observed (Bohm, 1979; Neumann et al., 2009). After media preparation sprouts of D. glomerata were planted in specific pots (eleven sprouts in each pot). The experiment was carried out in the phytotron with a 13/11 h light/dark regime. The day- and night-time air temperatures were 25 and $16^{\circ} \mathrm{C}$, respectively. The plants were watered with distilled water. The vegetative growth period lasted 42 days. The root systems of the test species were traced on foils placed on the transparent pot walls every 4-5 days during the first of three experimental weeks and every 2-3 days during the successive experimental weeks. When the experiment was terminated, the stems of plants were cut and roots were separated. The wet and dry (dried at $105^{\circ} \mathrm{C}$ ) biomass of stems and roots was measured. The number and length of plant roots were determined using the drawings of the root systems on foils. Roots were successively counted in the areas of $50 \mathrm{~cm}^{2}$ squares marked on foils and corresponding to the media depth of $1.5-8.5 \mathrm{~cm}$. In the same areas, the root lengths were measured using a curvemeter (Run-Mate ${ }^{\mathrm{TM}} \mathrm{Club}$ ) and were summed to obtain the total values per pot according to the method described by Bohm (1979). The wet and dry biomass of stems and roots, as well as the number and total length of the roots were used to calculate arithmetic mean values for all experimental series.

The soil penetration resistance is characterized by the force applied to the penetrating unit at a specified speed of penetration into the medium related to the unit area, $\mathrm{N} \mathrm{m}^{-2}$. In the present study penetration resistance was measured using a pentrologger (Eijkelkamp) equipped with a $5 \mathrm{~cm}^{2}$-base and $60^{\circ}$ cone, which was inserted into media with speed of $2 \mathrm{~cm} \mathrm{~s}^{-1}$. The resistance was measured at depth of $2.25-10 \mathrm{~cm}$. No meaningful results might be obtained at the lower depths. In order to minimize the wall-effect the pots used for these measurements were of larger size than those in the first experiment (the volume was $9.9 \mathrm{l}^{-1}$ ). The vegetation pots were of rectangular shape with length $33 \mathrm{~cm}$, width $20 \mathrm{~cm}$ and depth occupied by the soil $13.5 \mathrm{~cm}$. Such dimensions enabled to perform three measurements of penetration resistance (diagonally) in one pot. The distance between measurement points was about $8 \mathrm{~cm}$, the distance between two extreme points and short and long walls of pot was about $5 \mathrm{~cm}$.

For the purpose of this test, the same series of media were prepared as in the first experiment. Nine hundred nineteen seeds of $D$. glomerata were sown in each pot. The experiment was carried out in the phytotron under the same conditions as those in the first trial. In the first part of the experiment, the vegetative growth period lasted 6 weeks. The stems were then cut down in ten pots in each series but the roots were not separated. In five pots in each series the plants grew for 6 consecutive weeks under identical conditions as described above. After six and twelve weeks of plant growth, media of intact structure (roots were not separated) were adjusted to the state of field water capacity to measure the resistance to penetration (Eijkelkamp, 2010; Ślusarczyk, 1979). In each pot there were three resistance measurements, therefore, there were fifteen measurements for each media series. The results obtained were used for the calculation of mean values characterizing the experimental series (arithmetical mean values).

The statistical significance of differences between mean values characterizing the experimental series in the experiments was assessed using Student t-test or the AspinWelch v-test at the confidence coefficient $p=0.95$. Student t-test was used when variances for compared mean values did not differ significantly (the Fisher-Snedecor F-test). When variances differed significantly, the AspinWelch v-test was applied (Czermiński et al., 1992; Zgirski and Gondko, 1998).

\section{RESULTS AND DISCUSSION}

Results of the first experiment on the development of plant root systems are presented in Tables 4 and 5. The additions of the ion exchange substrate to sand affected the vegetation cycle of $D$. glomerata advantageously converting practically fruitless sand to a nutritious medium. Stem and root biomass of plants in series with substrate additions

T a b l e 4. Mean stem and root biomass of $D$. glomerata in the six week experiment

\begin{tabular}{|c|c|c|c|c|c|c|}
\hline \multirow{2}{*}{$\begin{array}{l}\text { Biomass } \\
\text { (g per pot) }\end{array}$} & \multicolumn{3}{|c|}{ Media series } & \multicolumn{3}{|c|}{ Biomass ratio } \\
\hline & S & $\mathrm{S}+1 \%$ & $\mathrm{~S}+2 \%$ & $(\mathrm{~S}+1 \%) / \mathrm{S}$ & $(\mathrm{S}+2 \%) / \mathrm{S}$ & $(\mathrm{S}+2 \%) /(\mathrm{S}+1 \%)$ \\
\hline Wet stem & $0.13 \pm 0.02 \mathrm{a}$ & $12.58 \pm 1.20 \mathrm{~b}$ & $16.31 \pm 2.33 \mathrm{c}$ & 94.62 & 122.62 & 1.30 \\
\hline Dry stem & $0.02 \pm 0.005 \mathrm{a}$ & $1.86 \pm 0.22 \mathrm{~b}$ & $2.36 \pm 0.38 \mathrm{c}$ & 77.63 & 98.38 & 1.27 \\
\hline Wet root & $0.43 \pm 0.05 \mathrm{a}$ & $13.17 \pm 1.95 \mathrm{~b}$ & $16.34 \pm 3.86 \mathrm{bc}$ & 30.35 & 37.65 & 1.24 \\
\hline Dry root & $0.07 \pm 0.016 \mathrm{a}$ & $1.60 \pm 0.21 \mathrm{~b}$ & $1.96 \pm 0.44 \mathrm{bc}$ & 22.51 & 27.62 & 1.23 \\
\hline
\end{tabular}

$\mathrm{S}-$ sand, $\mathrm{S}+1 \%$ - sand and $1 \%$ substrate mix, $\mathrm{S}+2 \%$ - sand and $2 \%$ substrate mix. Means followed by the different letters in the same row are significantly different, \pm- standard deviation, $\mathrm{n}=8$. 
T a b I e 5. Root number and total root length of $D$. glomerata in the six week experiment

\begin{tabular}{|c|c|c|c|c|c|c|}
\hline \multirow{2}{*}{$\begin{array}{c}\text { Vegetative } \\
\text { growth period } \\
\text { (day) }\end{array}$} & \multicolumn{3}{|c|}{ Media series } & \multicolumn{3}{|c|}{ Ratio for media series } \\
\hline & $\mathrm{S}$ & $\mathrm{S}+1 \%$ & $\mathrm{~S}+2 \%$ & $(\mathrm{~S}+1 \%) / \mathrm{S}$ & $(\mathrm{S}+2 \%) / \mathrm{S}$ & $(\mathrm{S}+2 \%) /(\mathrm{S}+1 \%)$ \\
\hline \multicolumn{7}{|c|}{ Mean root number } \\
\hline 11 & $5.8 \pm 0.7 \mathrm{a}$ & $8.0 \pm 3.1 \mathrm{ab}$ & $13.9 \pm 4.5 \mathrm{c}$ & 1.38 & 2.40 & 1.74 \\
\hline 15 & $11.3 \pm 1.8 \mathrm{a}$ & $20.6 \pm 5.4 b$ & $27.4 \pm 6.9 \mathrm{c}$ & 1.82 & 2.40 & 1.32 \\
\hline 20 & $18.9 \pm 3.6 \mathrm{a}$ & $38.3 \pm 9.5 b$ & $47.8 \pm 11.8 \mathrm{bc}$ & 2.03 & 2.53 & 1.25 \\
\hline 22 & $21.6 \pm 4.6 \mathrm{a}$ & $47.0 \pm 1.7 \mathrm{~b}$ & $63.8 \pm 19.9 \mathrm{bc}$ & 2.18 & 2.94 & 1.35 \\
\hline 24 & $23.5 \pm 5.0 \mathrm{a}$ & $56.5 \pm 11.1 \mathrm{~b}$ & $80.8 \pm 20.3 c$ & 2.40 & 3.42 & 1.42 \\
\hline 27 & $24.8 \pm 5.8 \mathrm{a}$ & $69.3 \pm 10.9 b$ & $92.8 \pm 17.9 \mathrm{c}$ & 2.79 & 3.75 & 1.34 \\
\hline 29 & $27.0 \pm 6.0 \mathrm{a}$ & $79.3 \pm 11.5 b$ & $104.9 \pm 19.6 \mathrm{c}$ & 2.94 & 3.87 & 1.32 \\
\hline 31 & $29.0 \pm 5.9 \mathrm{a}$ & $87.4 \pm 12.5 b$ & $117.8 \pm 21.8 \mathrm{c}$ & 3.01 & 4.05 & 1.34 \\
\hline 34 & $31.4 \pm 4.8 \mathrm{a}$ & $95.0 \pm 13.7 \mathrm{~b}$ & $128.1 \pm 23.1 \mathrm{c}$ & 3.03 & 4.08 & 1.35 \\
\hline 36 & $34.1 \pm 6.3 \mathrm{a}$ & $106.1 \pm \pm 5.2 \mathrm{~b}$ & $136.1 \pm 22.0 \mathrm{c}$ & 3.11 & 3.99 & 1.28 \\
\hline 38 & $37.0 \pm 6.6 \mathrm{a}$ & $111.9 \pm 16.4 \mathrm{~b}$ & $140.8 \pm 22.7 \mathrm{c}$ & 3.02 & 3.79 & 1.25 \\
\hline 41 & $38.5 \pm 7.0 \mathrm{a}$ & $119.6 \pm 18.2 b$ & $149.1 \pm 24.7 \mathrm{c}$ & 3.11 & 3.87 & 1.25 \\
\hline \multicolumn{7}{|c|}{ Mean total root length $(\mathrm{cm})$} \\
\hline 11 & $10.64 \pm 3.58 \mathrm{a}$ & $7.38 \pm 5.12 \mathrm{ab}$ & $13.11 \pm 3.97 \mathrm{ac}$ & 0.69 & 1.23 & 1.78 \\
\hline 15 & $18.71 \pm 3.93 \mathrm{a}$ & $27.90 \pm 13.25 \mathrm{ab}$ & $41.31 \pm 14.89 b c$ & 1.49 & 2.21 & 1.48 \\
\hline 20 & $28.36 \pm 5.33 \mathrm{a}$ & $67.74 \pm 19.18 b$ & $83.30 \pm 25.41 b c$ & 2.39 & 2.94 & 1.23 \\
\hline 22 & $31.63 \pm 6.91 \mathrm{a}$ & $79.63 \pm 21.77 b$ & $100.99 \pm 30.06 b c$ & 2.52 & 3.19 & 1.27 \\
\hline 24 & $33.70 \pm 7.87 \mathrm{a}$ & $92.58 \pm 22.52 b$ & $119.30 \pm 32.13 b c$ & 2.75 & 3.54 & 1.29 \\
\hline 27 & $36.30 \pm 8.98 \mathrm{a}$ & $110.23 \pm 22.38 b$ & $136.39 \pm 32.40 \mathrm{bc}$ & 3.04 & 3.76 & 1.24 \\
\hline 29 & $38.85 \pm 10.47 \mathrm{a}$ & $126.81 \pm 23.19 b$ & $156.69 \pm 36.79 \mathrm{bc}$ & 3.26 & 4.03 & 1.24 \\
\hline 31 & $41.31 \pm 11.48 \mathrm{a}$ & $144.91 \pm 26.58 b$ & $177.60 \pm 38.38 \mathrm{bc}$ & 3.51 & 4.30 & 1.23 \\
\hline 34 & $45.24 \pm 11.67 \mathrm{a}$ & $163.39 \pm 30.56 b$ & $199.29 \pm 43.97 b c$ & 3.61 & 4.41 & 1.22 \\
\hline 36 & $48.31 \pm 11.71 \mathrm{a}$ & $177.06 \pm 31.34 \mathrm{~b}$ & $213.70 \pm 41.44 b c$ & 3.66 & 4.43 & 1.21 \\
\hline 38 & $51.61 \pm 12.30 \mathrm{a}$ & $189.16 \pm 32.89 b$ & $220.18 \pm 43.28 b c$ & 3.66 & 4.27 & 1.16 \\
\hline 41 & $55.05 \pm 13.93 \mathrm{a}$ & $205.61 \pm 39.94 b$ & $233.21 \pm 50.38 \mathrm{bc}$ & 3.73 & 4.23 & 1.13 \\
\hline
\end{tabular}

Explanations as in Table 4.

was incomparably greater than in the controls. Differences in plant biomass between series $\mathrm{S}+1 \%$ and $\mathrm{S}+2 \%$ were much lower, namely $23-30 \%$. During the observation period, the morphological root parameters of D. glomerata in sand enriched with substrate additions were also significantly higher than those in the control series (Table 5). At the end of the experiment, the mean number and length of roots in the $50 \mathrm{~cm}^{2}$ cross-section through sand-1\% substrate mix were greater than in sand-only medium by 211 and $273 \%$, respectively. The mean number and length of roots found for the cross-section of the sand- $2 \%$ substrate mix were higher by 287 and $323 \%$, respectively than those for sand alone. The values of morphological root parameters obtained in series $\mathrm{S}+2 \%$ exceeded those for series $\mathrm{S}+1 \%$ during the whole observation period. However, their improvement was not proportional to the double increase of the ion exchange 
substrate in the experimental soil. At the end of the experiment, number and length of grass roots in the $50 \mathrm{~cm}^{2}$ cross-section of the sand- $2 \%$ substrate mix were higher than those for sand- $1 \%$ substrate mix by 25 and $13 \%$, respectively. The increase in root length obtained in series $\mathrm{S}+2 \%$ was not statistically significant compared to that for series $\mathrm{S}+1 \%$.

The increase in values of root morphological parameters after enriching sand with substrate additions indicated intensified development of root systems, which was partly due to the formation of more lateral roots. Among nutrients introduced together with the substrate nitrogen, phosphorus, calcium and magnesium are reported to affect development of plant lateral roots (Cao et al., 2013; Gruber et al., 2013; Rogers and Benfey, 2015). It was observed that $\mathrm{Mg}$ deficiency or deprivation decreased density or number of lateral roots in Arabidopsis thaliana (Gruber et al., 2013) and in Poncirus trifoliata (Cao et al., 2013). According to Cao et al. (2013) strict calcium deficiency resulted in reduced number of lateral roots in $P$. trifoliate as well. Furthermore, studies showed that under low P and $\mathrm{N}$ concentrations in media density or number of lateral roots in Arabidopsis increased (De Pessemier et al., 2013; Gruber et al., 2013; Niu et al., 2013). However, there are some reports showing the opposite tendencies. For instance, Fageria and Moreira (2011) informed about greater root branching in Zea mays with increasing levels of $\mathrm{N}$ fertilizer applied and Niu et al. (2013) reported that some Z. mays genotypes showed a decrease in the number of lateral roots under P deficiency. These reports agree with the results of our study because plants growing in the control series (sand without substrate addition, hence with very low N, P levels) produced less lateral roots than plants growing on sand supplemented with the ion exchange substrate.

It was demonstrated in many reports that plants exhibited intensive lateral root proliferation (Linkohor et al., 2002; Topp and Benfey, 2012; Trapeznikov et al., 2003; Yu et al., 2014) or increased root growth (Farley and Fitter, 1999; Jackson and Caldwell, 1989; Jing et al., 2010; Li et al., 2012) in nutrient-rich soil patches or nutrient-rich medium zones as compared to control weaker nutrient patches/zones. The studies described in references mentioned above had a localized nutrient supply where particular parts of the plant root system were in contact with patches/regions of a medium differing in nutrient concentrations. Such patches were absent in the sand-substrate mixture because sand particles were comparable to granules of ion exchangers in size, and both medium components were well mixed. Therefore, a mechanism of the phenomenon of enhanced root growth under conditions of a heterogeneous distribution of nutrient ions is probably different from the one observed in our studies.

Results of the second experiment on the soil penetration are presented in Fig. 1. After six weeks of plant growth the media penetration resistance in series with substrate additions, ie $\mathrm{S}+1 \%$ and $\mathrm{S}+2 \%$, was significantly higher than that of control medium at depth of $2.5-8.0 \mathrm{~cm}$ and $2.5-7.25 \mathrm{~cm}$, respectively (Fig. 1a). The greatest differences in resistance between control medium and sand supplemented with the substrate were found at the depth of 3.3-4.0 $\mathrm{cm}$. In both fertilized media the resistance values exceeded that of the sand alone by $50 \%$. Above and below these layers the differences in resistance between the control and fertilized series decreased. The differences in resistance values between the samples with 1 and $2 \%$ substrate were not statistically significant and generally did not exceed $10 \%$.

The penetration resistance of media in series with 1 and $2 \%$ substrate additions after twelve weeks of plant growth was significantly higher than that of control sand at the whole analyzed depth (Fig. 1b). The highest resistance values in the medium supplemented with $1 \%$ substrate were observed at the depth of $3.5-4.0 \mathrm{~cm}$ where this parameter was 2.5 times greater than that found for sand alone. At the same depth the highest difference in the penetration resistance was observed between sand alone and sand$2 \%$ substrate mix - in this case resistance value was two times greater than that for the controls. Resistance values for both fertilized series decreased above and below the depth of 3.5-4.0 cm; however, until the depth of $8 \mathrm{~cm}$ they exceeded values determined for the control series by about $20 \%$. The higher resistance of sand-substrate mixtures can be explained by more intensive development of plant root systems. The results of the first experiment showed that the substrate additions to sand significantly increased number and length of roots. Therefore, root system formed a specific mesh that bound sand particles, so that the media had greater penetration resistance. Such media would be less susceptible to the destructive action of wind and water and therefore more resistant to erosion.

The effect of increasing the resistance for used substrate doses depended on the duration of plant growth. After twelve weeks of grass growth the resistance to penetration of media supplemented with substrate additions at the whole analyzed depth was significantly greater as compared to that measured after six weeks of plant growth (Fig. 2). The greatest differences in values of resistance between fertilized media were at the depth of 2.5$4.5(5.0) \mathrm{cm}$. In both fertilized media after twelve weeks of grass growth, resistance values in these layers exceeded those measured for media after six weeks of grass growth by $50-96 \%$ (Fig. 2 ).

The enhanced increase in penetration resistance to the specific depth observed in our study (especially after twelve weeks of plant growth in series with substrate additions) is consistent with observations of other authors (Głąb, 2013a; Laboski et al., 1998; Zhao et al., 2010). However, reasons for their measured increases in penetration resistance were different from the one found in our case. For instance, Glab (2013a) explained an enhanced increase in penetration 
a

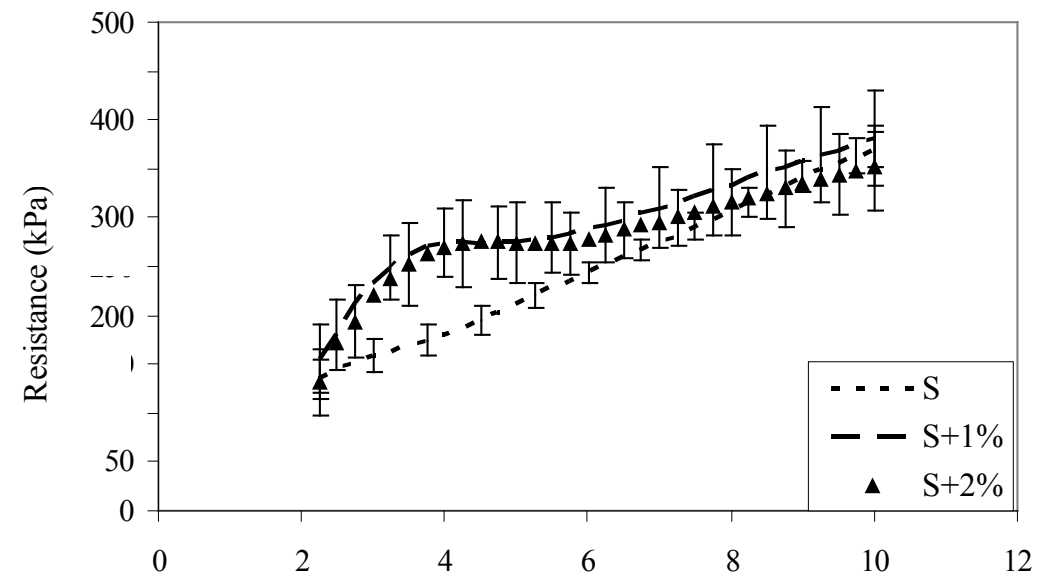

b

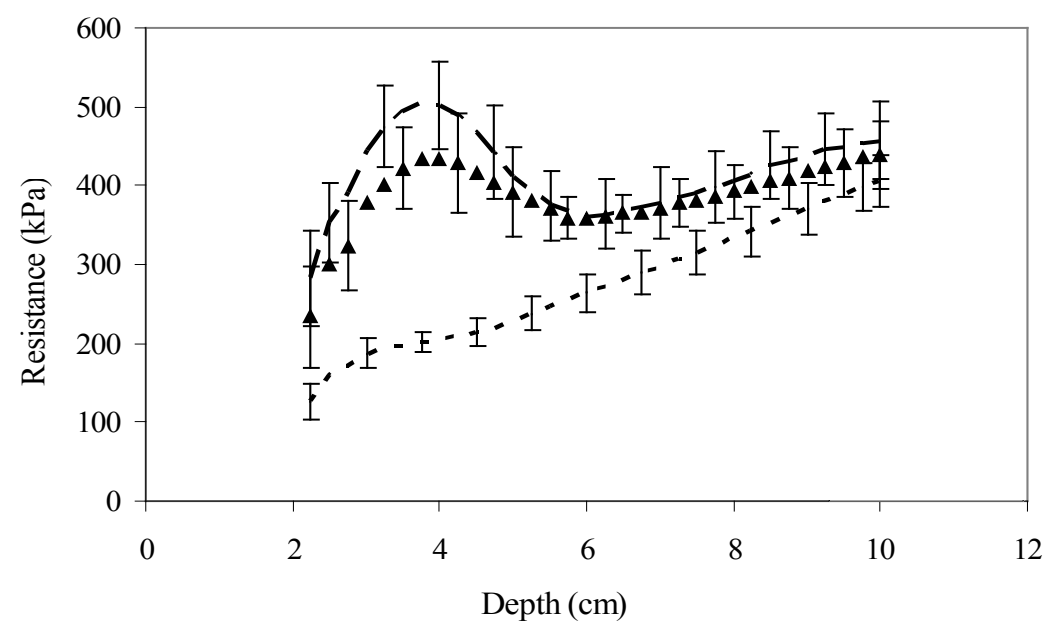

Fig. 1. The resistance to penetration of media as a function of the depth after: $a-6$, and $b-12$ weeks of plant growth (I - standard deviation, $\mathrm{n}=15)$.

resistance at the depth of 0-20 $\mathrm{cm}$ by greater compaction of topsoil caused by vehicle traffic. Laboski et al. (1998) found under $Z$. mays cultivation that an increase in penetration resistance of sandy soil at depth of $0.15-0.35 \mathrm{~m}$ was caused by the presence of natural compacted layer.

In our study, as it was described above, the influence of intensity of root growth on penetration resistance was observed. However, the results reported in some papers (Głąb and Szewczyk, 2014) do not indicate the aforementioned dependence. The penetration resistance is widely used as one of indicators of soil compaction and its influence on root morphology and architecture is often discussed (Aggarwal et al., 2006; Głąb, 2013b). The changes in soil compaction (and penetration resistance, respectively) significantly modify water properties of the soil such as infiltration ability and plant available water capacity (Głąb and Szewczyk, 2014; Zhang et al., 2006). In heavy soils, the increased compaction (and hence - greater penetration resistance) negatively affects the plant root growth.
Whereas in the investigated sandy medium, the increase in penetration resistance can be a reflection of improved plant available water capacity connected with increasing percentage of mezo- and micropores. It can also positively modify the intensity of root growth and this phenomenon can result in a further increase in penetration resistance along with the progressing development of plants.

\section{CONCLUSIONS}

1. The minor additions of ion exchange substrate into sand $(1$ and $2 \% \mathrm{v} / \mathrm{v})$ strongly intensified the growth of Dactylis glomerata L., used as a test culture, and development of its root system. That caused a significant improvement of the sandy medium cohesion reflected in increasing its penetration resistance reaching $250 \%$ at the depth of $3.5 \mathrm{~cm}$ already in 12 weeks vegetation period.

2. Sand media supplemented with 1 and $2 \% \mathrm{v} / \mathrm{v}$ substrate addition did not differ significantly between each other in penetration resistance. 


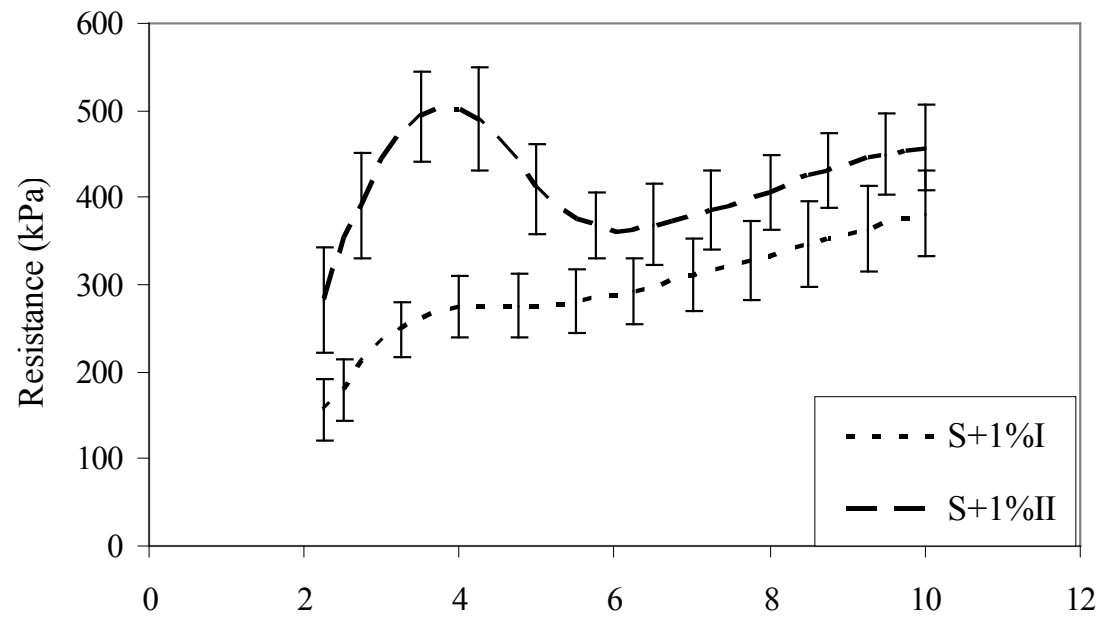

b

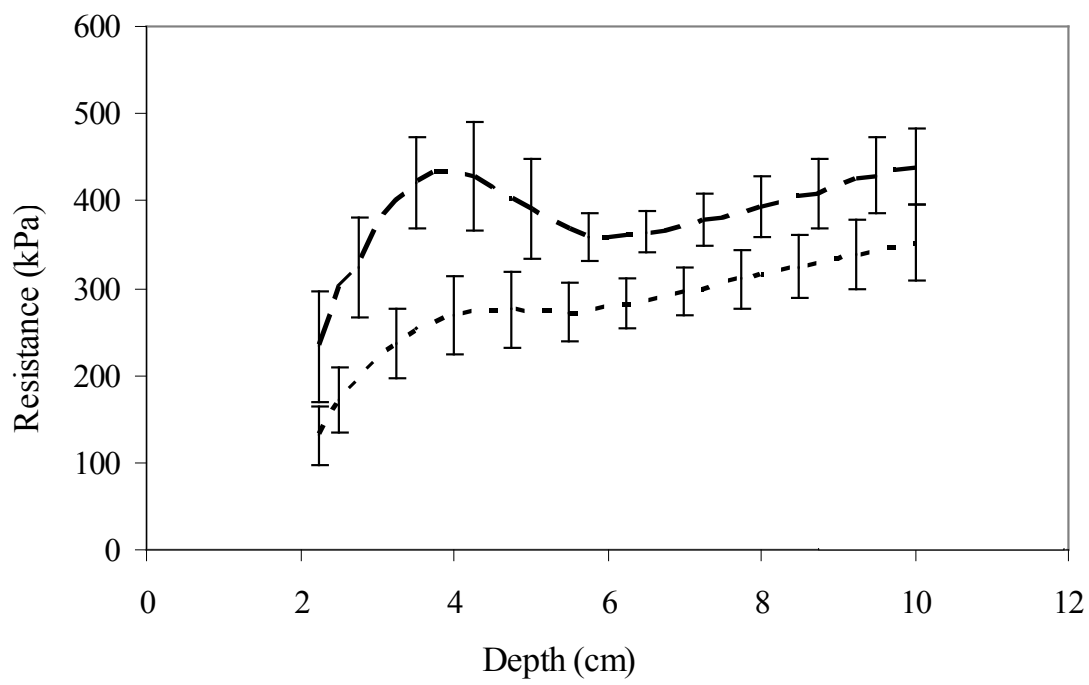

Fig. 2. Changes in mean resistance of: $a-S+1 \%$ and $b-S+2 \%$ substrate mix with depth after six $(S+1 \% \mathrm{I})$ and twelve $(\mathrm{S}+1 \% \mathrm{II})$ weeks of plant growth (I - standard deviation, $\mathrm{n}=15)$.

3. Addition of $1 \%$ of the substrate can be recommended as a mean causing intensive plants growth on barren sands and improvement of the sandy soils cohesion.

Conflict of interest: The Authors do not declare conflict of interest.

\section{REFERENCES}

Aggarwal P., Choudhary K.K., Singh A.K., and Chakraborty D., 2006. Variation in soil strength and rooting characteristics of wheat in relation to soil management. Geoderma, 136, 353-363.

Bohm W., 1979. Methods of studying root systems. Springer, Berlin, Heidelberg, New York.

Cao X., Chen C., Zhang D., Shu B., Xiao J., and Xia R., 2013. Influence of nutrient deficiency on root architecture and root hair morphology of trifoliate orange (Poncirus trifoliata L. Raf.) seedlings under sand culture. Sci. Hort., 162, 100-105.
Czermiński J.B., Iwaszewicz A., Paszek Z., and Sikorski A., 1992. Statistical methods for chemists (in Polish). PWN, Warsaw, Poland.

De Pessemier J., Chardon F., Juraniec M., Delaplace P., and Hermans C., 2013. Natural variation of the root morphological response to nitrate supply in Arabidopsis thaliana. Mech. Develop., 130, 45-53.

Eijkelkamp Agrisearch Equipment, 2010. Pentrologger. Operating instructions. Giesbeek, Netherlands.

Fageria N.K. and Moreira A., 2011. The role of mineral nutrition on root growth of crop plants. In: Advances in Agronomy (Ed. D.L. Sparks). Academic Press, San Diego, CA, USA.

Farley R.A. and Fitter A.H., 1999. The responses of seven cooccurring woodland herbaceous perennials to localized nutrient-rich patches. J. Ecol., 87, 849-859.

Gląb T., 2013a. Effect of tractor traffic and $N$ fertilization on the root morphology of grass/red clover mixture. Soil Till. Res., 134, 163-171. 
Gląb T., 2013b. Impact of soil compaction on root development and yield of meadow-grass. Int. Agrophys., 27, 7-13.

Gląb T. and Szewczyk W., 2014. Influence of simulated traffic and roots of turfgrass species on soil pore characteristics. Geoderma, 230-231, 221-228.

Gruber B.D., Giehl R.F.H., Friedel S., and Wirén N., 2013. Plasticity of the arabidopsis root system under nutrient deficiencies. Plant Physiol., 163, 161-179.

Jackson R.B. and Caldwell M.M., 1989. Timing and degree of root proliferation in fertile-soil microsites for three colddesert perennials. Oecologia, 81, 149-53.

Jing J., Ruia Y., Zhanga F., Rengelb Z., and Shena J., 2010. Localized application of phosphorus and ammonium improves growth of maize seedlings by stimulating root proliferation and rhizosphere acidification. Field Crop. Res., 119, 355-364.

Laboski C.A.M., Dowdy R.H., Allmaras R.R., and Lamb J.A., 1998. Soil strength and water content influences on corn root distribution in a sandy soil. Plant Soil, 203, 239-247.

Li H.B., Zhang F.S., and Shen J.B., 2012. Contribution of root proliferation in nutrient-rich soil patches to nutrient uptake and growth of maize. Pedosphere, 22, 776-784.

Linkohor B.I., Williamson L.C., Fitter A.H., and Ottoline Leyser H.M., 2002. Nitrate and phosphate availability and distribution have different effects on root system architecture of Arabidopsis. Plant J., 29(6), 751-760.

Lityński T. and Jurkowska H., 1982. Soil fertility and plant nutrition (in Polish). PWN, Warsaw, Poland.

Maciak F., 1999. Protection and restoration of the environment (in Polish). SGGW Press, Warsaw, Poland.

Neumann G., Timothy S.G., and Plassard C., 2009. Strategies and methods for studying the rhizosphere - the plant science toolbox. Plant Soil, 321, 431- 456.

Niu Y.F., Chai R.S., Jin G.L., Wang H., Tang C.X., and Zhang Y.S., 2013. Responses of root architecture development to low phosphorus availability: a review. Ann. Bot., 112, 391-408.

Ostrowska A., Gawliński S., and Szczubiałka Z., 1991. Methods for analysis and evaluation of soil and plant properties (in Polish). Institute of Environmental Protection, Warsaw, Poland.

Qian P. and Schoenau J.J., 2002. Practical applications of ion exchange resins in agricultural and environmental soil research. Can. J. Soil Sci., 82, 9-21.
Rogers E.D. and Benfey P.N., 2015. Regulation of plant root system architecture: implications for crop advancement. Curr. Opin. Biotech., 32, 93-98.

Sochan A., Bieganowski A., Ryżak M., Dobrowolski R., and Bartmiński P., 2012. Comparison of soil texture determined by two dispersion units of Mastersizer 2000. Int. Agrophys., 26, 99-102.

Soldatov V.S., 1988. Ion exchanger mixtures used as artificial nutrient media for plants. In: Ion Exchange for Industry (Ed. M. Streat). Ellis Horwood, London, UK.

Soldatov V.S., 1998. Potentiometric titration of ion exchangers. React. Funct. Polym., 38, 73-112.

Soldatov V.S., Pawłowski L., Kloc E., Szymańska M., and Matusevich V.V., 1997. Remediation of depleted soils by addition of ion exchange resins. Ecol. Eng., 8, 337-345.

Soldatov V.S. and Perishkina H.G., 1985. Artificial soils for plants (in Russian). Nauka i Technika, Minsk, Belarus.

Ślusarczyk E., 1979. Determination of useful retention of mineral soils for forecasting and design of irrigation (in Polish). Melior. Roln., 3(53), 1-10.

Topp C.N. and Benfey P.N., 2012. Growth control of root architecture. In: Plant biotechnology and agriculture. Prospects for the 21st century (Eds A. Altman, P.M. Hasegawa). Academic Press, London, UK.

Trapeznikov V.K., Ivanov I.I., and Kudoyarova G.R., 2003. Effect of heterogeneous distribution of nutrients on root growth, ABA content and drought resistance of wheat plants. Plant Soil, 252, 207-214.

Wasąg H., Pawłowski L., Soldatov V.S., Szymańska M., Chomezyńska M., Kołodyńska M., Ostrowski J., Rut B., Skwarek A., and Mlodawska G., 2000. Restoration of degraded soils using ion exchange resins (in Polish). KBN No. 3 T09 C 10514 Research Report, Lublin University of Technology, Lublin, Poland.

Yu P., White P.J., Hochholdinger F., and Li C., 2014. Phenotypic plasticity of the maize root system in response to heterogeneous nitrogen availability. Planta, 240, 667-678.

Zhang S., Grip H., and Lovdahl L., 2006. Effect of soil compaction on hydraulic properties of two loess soils in China. Soil Till. Res., 90, 117-125.

Zhao D., Wright D.L., Marois J.J., Mackowiak C.L., and Brennan M., 2010. Improved growth and nutrient status of an oat cover crop in sod-based versus conventional peanutcotton rotations. Agron. Sustain. Dev., 30, 497-504.

Zgirski A. and Gondko R., 1998. Biochemical calculations (in Polish). PWN, Warsaw, Poland. 